\title{
El sentido del humor en las tres primeras novelas de V. S. Naipaul
}

\author{
Nair María ANAYA FERREIRA* \\ Universidad Nacional Autónoma de México
}

El mundo real se encuentra en algún otro lugar. Partiendo de esa base, ¿cómo es posible entonces tener una identidad genuina y buscar la felicidad? Ésa es, quizá, la pregunta que sustenta la mayor parte de la obra de V. S. Naipaul, escritor nacido en Trinidad y Tobago en 1932 y avecindado en Inglaterra desde 1950. La respuesta es compleja y conlleva no sólo una reflexión psicológica acerca de la identidad individual en el mundo contemporáneo sino también un profundo cuestionamiento sobre las consecuencias del fenómeno colonial. Para Naipaul, el enigma no radica en el ¿quién soy?, es decir, en la búsqueda interior para alcanzar algún tipo de completud. De entrada, este concepto le resulta ajeno pues, en el Caribe, el rompimiento del individuo con su entorno geográfico inmediato (resultado de las migraciones forzadas de África y Asia) y con su pasado histórico (como consecuencia de su educación colonial) genera sujetos vacíos, carentes de iniciativa que, en última instancia, están condenados al fracaso debido al vacío cultural que los rodea.

Éste es uno de los aspectos más pesimistas de la visión literaria de Naipaul, y la razón por la que su obra desata amargas controversias. Sin embargo, en sus primeras novelas - aquellas escritas durante las décadas de los cincuentas y sesentas-, el ganador del Premio Nobel de 2002 maneja estos temas con un grado de comicidad y afecto que los críticos extrañan en su obra posterior, Ia cual se caracteriza por una densidad narrativa que apenas esconde la desesperanza y el permanente exilio espiritual del hombre contemporáneo. El propósito de este ensayo será explorar la forma en que el manejo del sentido del humor define el distanciamiento afectivo e intelectual de Naipaul con respecto a su país de origen. Se puede afirmar que existe una relación directa entre los recursos narrativos empleados en las primeras obras y el gradual ensombrecimiento que caracteriza su visión literaria y política;

* La investigación para este artículo contó con el apoyo del proyecto PAPIIT número IN401599. 
es decir, la comedia sentimental y la descripción irónica de las clases bajas de Trinidad en la primera mitad del siglo Xx constituyen lu estrategia narrativa e ideológica por medio de la cual Naipaul logró romper con los demonios de su pasado, una forma de vida de la que siempre quiso escapar, física, psicológica y espiritualmente. Dentro de las primeras obras - The Mystic Masseur (1957), The Suffrage of Elvira (1958), Miguel Street (1959) y A House for Mr. Biswas (1961) - existe un hilo conductor que concluye en la novela de 1967 The Mimic Men, la cual cierra el ciclo ficcional caribeño del autor y, por así decirlo, concluye también la etapa que podría definirse como más "sutil" o "liviana" (si es que estos adjetivos pueden ser alguna vez adecuados para definir a Naipaul).

La vida literaria de Naipaul ha estado marcada por su profunda conciencia de ser un individuo desarraigado en busca de un orden que sólo puede encontrar por medio de la representación, de ahí que su obra sea emblemática de algunos de los temas primordiales de la teoría y la literatura poscoloniales. Para él, una de las consecuencias más devastadoras del fenómeno imperial del siglo XIX y de la situación colonial que éste generó a lo largo y ancho del planeta fue el hecho de que a los pueblos no-europeos se les negó la posibilidad de vivir experiencias plenas y gratificantes, así como de alcanzar una dimensión trascendental de la existencia. Sin embargo, su visión no se limita a la enajenación sufrida por los individuos periféricos (en su caso los que viven en el Caribe), condenados a ser meros imitadores de las realidades europeas, sino que se extiende a la imposibilidad misma de dichas culturas para representarse a sí mismas. Desde su punto de vista, las culturas periféricas carecen de orden porque carecen de poder de representación, entre otras razones porque no tienen una tradición artística que les permita llegar a esa trascendencia espiritual tan necesaria para el ser humano. El escritor, al igual que los individuos de su sociedad, no puede escapar a su sino y, puesto que en su entorno no existen temas con la magnitud suficiente para ser tratados en obras literarias, está también sentenciado a simplemente parodiar y remedar las principales formas del viejo continente.

Casi como ejemplo sacado de un libro de texto, la vida y la obra de Naipaul pueden ser consideradas como paradigma del problema de la enajenación colonial del individuo, el cual fue inicialmente explorado por Frantz Fanon en Peau Noire, Masques Blancs (1952), en donde el psicoanalista martiniqués sugiere que el individuo colonizado padece un complejo de inferioridad consecuencia no sólo del dominio político y económico de la metrópolis sino de la interiorización individual y colectiva de dicha inferioridad debido a los procesos europeos de representación (Fanon 1952: 28). Aunque en su análisis Fanon se refería específicamente a los negros que habitaban en Fran- 
cia en los años cuarentas y cincuentas, su planteamiento ha sido retomado por diversos críticos con respecto a la situación del individuo colonizado en general. Entre éstos, cabe destacar la obra de Homi Bhabha, quien, a partir de Fanon, interroga el concepto de identidad dentro del contexto teórico de la situación poscolonial y ofrece al lector puntos de reflexión sobre la controvertida postura de Naipaul.

Para Bhabha, la principal contribución de Fanon, más que en su búsqueda de una transformación total del hombre y la sociedad, radica en el hecho de que este intelectual se sitúa en los ambiguos intersticios del cambio histórico, es decir, que escribe desde "el área de ambivalencia entre la raza y la sexualidad; a partir de una contradicción no resuelta entre cultura y clase; desde lo profundo de la lucha entre representación psíquica y realidad social" (Bhabha 1994: 40). Su verdad es transgresora y de transición. Para Fanon, la posibilidad de que exista una identificación absoluta entre hombre y sociedad queda vedada para las sociedades colonizadas, pues en ellas los actos enajenantes del gobierno colonial —en su afán por civilizar o modernizar a las poblaciones autóctonas- convierten a las instituciones en caricaturas de otras que alguna vez fueron productivas, y a los individuos en seres paródicos inscritos en la grieta que surge entre la conciencia colonial y la sociedad que los rodea. Se crea así, dice Bhabha, un "delirio maniqueo" en el que prevalece la ambivalencia del ser; es decir, el Ser no se identifica a partir de su confrontación con el Otro, sino que se convierte en su propia imagen enajenada y se concibe a sí mismo como la otredad del Ser "inscrito en el perverso palimpsesto de la identidad colonial" (Bhabha 1994: 43-44).

Más allá de las críticas muchas veces superficiales que se le pueden hacer a Naipaul por su imagen de un Tercer Mundo condenado a la ignorancia, la violencia y la vulgaridad, se puede decir que la contribución literaria de su obra radica en la forma en la que, dentro de una misma línea narrativa, no sólo identifica, articula y describe las carencias económicas, sociales y vivenciales de dichas sociedades, sino que reflexiona también acerca de los procesos europeos de representación de esas comunidades y, dando un paso más adelante, incorpora y crea una visión muy personal tanto de las comunidades como de los procesos de representación. Y lo que surge de este palimpsesto no agrada a muchos, pues parece condenar inexorablemente a los pueblos subdesarrollados al delirio maniqueo planteado por Fanon. Es decir, niega a estos pueblos toda posibilidad de evolución política y de trascendencia histórica y cultural.

A raíz de la obtención del Premio Nobel y otros galardones, podría parecer que Naipaul es uno de los pocos escritores caribeños de expresión ingle- 
sa - junto con Derek Walcott- que ha destacado a nivel internacional. Sin embargo, no es así. Antes de pasar a un análisis de sus tres primeras obras narrativas, creo conveniente ofrecer un breve panorama del contex to literario en el que surgió a la fama, el cual nos ayuda a comprender las razones que subyacen su elección de temas y a ver con mayor claridad la magnitud de su realización literaria.

El Caribe ha tenido, desde el siglo XIX, una prolífica producción literaria en inglés, la cual encuentra difusión en pequeñas editoriales e innumerables publicaciones periódicas. Sin embargo, a partir de 1950 tuvo lugar una explosión creativa que, paradójicamente, fue consecuencia del exilio voluntario o involuntario de una gran cantidad de caribeños que fueron a residir a Inglaterra, en especial a Londres. Al terminar la Segunda Guerra Mundial, hubo una enorme migración masiva de trabajadores provenientes de casi todos los rincones del imperio, los cuales eran reclutados como mano de obra en industrias y servicios en los que los mismos ingleses ya no querían participar. Además, dentro de la política de aculturación de los pueblos coloniales, los estudiantes destacados acudían a las principales universidades, sobre todo a Oxford y Cambridge, a concluir la educación inglesa que habían recibido en sus países de origen. En pocos años, Londres se transformó en la "capital literaria" del Caribe, el objetivo principal de quienes querían escapar del estancamiento cultural, político y social de las islas.

Paradójicamente, la diáspora y el exilio intensificaron el debate acerca de la naturaleza y los propósitos de la producción cultural caribeña, y los escritores se encontraron en una posición en la que los planteamientos expresados por Fanon adquirieron especial relevancia. Como ciudadanos y como creadores culturales tenían sentimientos ambivalentes hacia su país de origen pero también hacia el país que los acogió y, de una manera o de otra, todos tenían que afrontar la sensación de pertenecer a una periferia que, desde el exilio, acentuaba su doble desarraigo: la falta de identificación con las condiciones vigentes en el Caribe y la falta de identidad con una tradición inglesa que demoró en reconocerlos.

En este contexto, la decisión de escribir sobre temas y personajes isleños podía ser descartada por los críticos como una forma de exotismo superficial aunque, al mismo tiempo, constituía una búsqueda genuina de identidad para los escritores. En el caso de Naipaul, el dilema adquiría especial trascendencia, pues se cuestionaba el hecho de que la realidad caribeña pudiera encajar dentro de los géneros literarios europeos o, peor aún, ser siquiera un sujeto apropiado para los modelos literarios del Viejo Mundo. Sin embargo, el establishment británico, con su enorme capacidad de absorción, se encargó de ofrecer las salidas adecuadas para ese tipo de in- 
quietudes en la forma de programas de radio transmitidos por la $\mathrm{BBC}$, en los que los escritores de las colonias podían dar voz a su creatividad y encontrar la audiencia apropiada: el país de origen. En el caso del programa Caribbean Voices, Naipaul encontró no sólo una oportunidad laboral, sino también el foro donde discutir sus preocupaciones literarias con autores de la talla de Sam Selvon, George Lamming, Edgar Mittelhorzer y otros (Donnell 1996: 206-216).

Fue durante esta época, a mediados de la década de los cincuentas y principios de los sesentas, cuando Naipaul publicó los libros que le ganaron prestigio internacional y que muestran algunos de los rasgos que lo han distinguido a lo largo de seis décadas: un profundo interés por el individuo atrapado en una sociedad inestable, en la que el choque entre los valores metropolitanos y los locales impiden toda posibilidad de obtener logros personales y de alcanzar un desarrollo social genuino. Sin embargo, lo que da significancia a estas obras es la capacidad del autor para recrear, desde un punto de vista cómico, la vivacidad y el bullicio de una sociedad multicultural en constante proceso de transformación. La caracterización de personajes, en su mayoría de clase baja, constituye el medio por el que Naipaul buscó los caminos necesarios para llegar a lo que en su opinión era un género ajeno a la realidad caribeña: la novela. Estas novelas son, en cierto sentido, experimentales, pues transmiten la búsqueda del autor por una voz que pueda reflejar la vida del Caribe y al mismo tiempo formar parte de la tradición literaria inglesa que constituía su marco de referencia.

Naipaul es, entonces, un autor que encarna la problemática de sus propios personajes, pero con una diferencia: él sí logra trascender su limitado entorno gracias a la literatura. Esta dualidad paradójica es lo que convierte a sus novelas en críticas mordaces de la situación poscolonial. La trama de las cuatro novelas deja entrever un panorama de la historia de Trinidad de los años treintas a los cincuentas, un periodo de efervescencia política en el que la población luchaba por la autodeterminación de la isla y buscaba reacomodar fuerzas entre los grupos dominantes, en especial los de origen africano que trabajaban sobre todo en los campos petroleros, y los que provenían de la India, campesinos por contrato que formaban ya la clase media. Éste es el entorno en el que se mueven los personajes de las cuatro novelas. En Miguel Street, la sucesión de viñetas independientes muestra de modo fragmentado la vida de algunos individuos marginados, en su lucha por sobrevivir. Pobretones sin futuro, cubren apenas sus necesidades básicas, de tal forma que cualquier situación que sale de la rutina se convierte en un acontecimiento extraordinario a la vista de los demás. Muchas de las historias eran, de hecho, anécdotas comunes en Puerto España (Cudjoe 1988: 
19), pero Naipaul les da un giro para hacer hincapié en el tema que lo obsesiona: el de la imitación y el mimetismo.

Los personajes de Miguel Street, cada uno protagonista de su propia anécdota, son individuos fracasados que intentan crearse una imagen pública que de sentido a su vida. Su lucha, por tanto, no es una lucha genuina por una identidad propia, sino una especie de adaptación constante a un entorno que se rige por valores contradictorios. Envuelto en un vacío cultural, cada personaje se construye una máscara que le permite ser alguien ante los demás, pero que también, en última instancia, los llevará a la destrucción: el tímido Bogart, por ejemplo, homónimo del actor estadounidense, abandona su sastrería para regresar años después convertido en un ser misterioso que provoca la admiración de todos sus amigos. Después de recorrer Guyana y zonas de Brasil en negocios ilícitos y tráfico de mujeres, es encarcelado cuando era el próspero gerente de un burdel. Después de dos desapariciones más retorna con acento estadounidense, es escandaloso y se dedica a comprar dulces y coca colas a los niños del lugar, sólo para ser detenido por bigamia. El final es un anticlímax, pero ése es justo el propósito de Naipaul. Los cuentos son narrados con ingenio y sentido del humor, lo cual se torna doblemente irónico cuando observamos que el narrador es un niño que se dedica a hacer letreros y carteles para los negocios de estos hombres fracasados. La narración está teñida por sentimientos ambivalentes de admiración, miedo y, a veces, compasión; no obstante, lo que resalta es la distancia narrativa que se establece entre el niño y los sujetos a los que describe, una distancia que esconde juicios de valor determinados, a final de cuentas, por una cultura hegemónica, ajena a la realidad de la calle Miguel (metonimia de las zonas marginadas de Puerto España).

El lector se ve envuelto en la engañosa dinámica narrativa de los cuentos. Siguiendo la inocente mirada del niño, quien conoce y estima a los personajes, el lector se entera de los intentos frustrados de Black Wordsworth por alcanzar la dimensión poética de su homónimo blanco; de Popo, el carpintero que busca originalidad pero no logra construir nada —ni siquiera "la cosa sin nombre" que tanto intrigaba al narrador (Naipaul 1959: 21)—y sólo logra cierta solvencia económica cuando vende muebles robados y es detenido por ello, con lo que adquiere fama entre sus vecinos; de Man-man, el predicador que cree que es el nuevo mesías; de Elias, que sueña con ser doctor pero reprueba todos los exámenes, etcétera. Sin embargo, a pesar de la fluidez de la narración y de la aparente objetividad con que se desenvuelven los cuentos, el lector va quedando atrapado en la sutil ironía de cada historia. La búsqueda de cada personaje por forjarse un nuevo rol constituye de hecho el parámetro de su fracaso, y aun cuando alguno de los persona- 
jes pueda tener un éxito personal, éste se empequeñece porque aparece a los ojos del lector como un acto de rendición frente a un sistema de valores ajenos. Es decir, los personajes sólo tratan de adaptarse, de encajar, pero nunca buscan verdaderamente la superación personal.

Hacia el final del libro, la paradójica técnica narrativa por medio de la cual el lector se siente a la vez familiarizado y distanciado de la vida de estos personajes se cierra aún más en el último cuento de la colección, cuando la madre del narrador, asustada de que el chico lleva una vida desenfrenada y no hace más que beber y visitar burdeles, decide que debe sacarlo de Trinidad. Y aquí es donde el lector comprende, finalmente quizás, en qué radica el sentido del humor de la colección. No es que los personajes sean esencialmente cómicos, ni que tengan rasgos tan atractivos que los vuelvan inolvidables, como en el caso de Charles Dickens. La comicidad reside en el esfuerzo constante de los personajes por encajar en un sistema que les resulta incongruente: por un lado, están los valores de su entorno inmediato, un entorno que fomenta la deshonestidad, el dinero fácil y un hedonismo tan instintivo que pierde toda dimensión moral; por el otro, los valores hegemónicos no sólo de las instituciones inglesas que rigen la sociedad, sino de las propias culturas transplantadas -en especial la que proviene de la India - los cuales han perdido su significado real en el nuevo entorno. El último cuento permite al lector confrontar esta dualidad y comprender, al mismo tiempo, el funcionamiento humorístico de todo el libro. Después de una terrible y dolorosa borrachera, el muchacho tiene una especie de revelación y le dice a su madre: "No es mi culpa, en realidad. Es sólo Trinidad. ¿Qué otra cosa puede hacer alguien aquí excepto beber?" (Naipaul 1959: 167). Es decir, el entorno producido por el colonialismo niega toda posibilidad de desarrollo individual. Incluso las posibilidades de escape se ven determinadas por el mundo exterior, sin ninguna participación del libre albedrío del muchacho. El hombre influyente de la comunidad - Ganesh Pundit, quien será el protagonista de la siguiente novela The Mystic Masseur - le ofrece la única beca disponible para estudiar en Londres: no para estudiar ingeniería, ni derecho, sino "drogas". La ambigüedad produce su efecto cómico, pues significa algo diferente para cada quien: para el muchacho conjura la visión de un simple vendedor de lápices labiales, algo en lo que ciertamente no se quiere convertir, y para sus amigos la imagen de riqueza sin esfuerzo. En cualquier caso, es mejor que una beca para no estudiar pues, como explica Ganesh Pundit: "El gobierno todavía no regala ese tipo de becas. Sólo los ministros [secretarios de estado] pueden hacerlo". Párrafos más adelante, cuando el narrador resume los trámites realizados antes de viajar, comenta que: "Los estadounidenses me 
dieron una visa después de hacerme jurar que no derrocaría a su gobierno a mano armada" (Naipaul 1959: 169). Comentarios de este tipo son los que caracterizan la voz narrativa de Miguel Street y transforman a la aparente sencillez y comicidad de los cuentos en una incisiva pero tendenciosa crítica a la realidad caribeña.

Las siguientes novelas, The Mystic Masseur y The Suffrage of Elvira, elaboran aún más las incongruencias manifestadas en la colección de cuentos. En Miguel Street, cada cuento ofrece un vislumbre de la vida de cada personaje y su interrelación con el medio pero, sobre todo, aunque de forma encubierta, del desarrollo personal y psicológico del niño-muchacho narrador. No obstante, la fragmentación deja ver también la búsqueda por parte del joven Naipaul, recién egresado de la Universidad de Oxford, de las estrategias narrativas y la voz apropiada para recrear la vida en el Caribe. Y el experimento funcionó. A partir de la colección de cuentos (la cual fue publicada después de las dos novelas), Naipaul tuvo ya capacidad de desarrollar narraciones más largas alrededor de un motivo subyacente: la transformación de ciertos individuos emprendedores dentro de un entorno político mucho más amplio.

La trama de las dos novelas está insertada en el complejo proceso de transformación política que sufrió Trinidad desde finales de la década de los veintes hasta principios de los sesentas. Al igual que en la colección de cuentos, la caracterización de los personajes se centra más en su modo de adaptarse a este escenario cambiante que en una construcción genuina de los rasgos que los individualizan. El hilo conductor es el sentido de enajenación que sufren los personajes principales ante la imposibilidad de vivir de acuerdo con los valores ancestrales de su país de origen, lo cual limita sus oportunidades de independizarse y de insertarse en una sociedad más amplia, fuera de la jurisdicción de su grupo étnico, el de los hindúes. Dos rasgos definen este proceso de enajenación: por un lado, los personajes no tienen una conciencia clara de la ruptura gradual con su pasado; por el otro, tratan de adquirir una identidad prestada y, cuando lo logran, se convierten en simples remedos tanto de sus orígenes como de la cultura que los absorbió, la inglesa. Es decir, carecen de una identidad.

Éste ha sido uno de los puntos más criticados en la obra de Naipaul, pues parece que el autor descarta de tajo toda posibilidad de integración racial y cultural. En su mayoría, los personajes se mueven dentro de sus propias comunidades y el mestizaje es una característica casi inexistente. Cuando llega a haberlo, como en el caso de Hok, el chico de origen chino, europeo y africano en The Mimic Men, los personajes se sienten completamente avergonzados de su genealogía. Las novelas se convierten, entonces, en reflexio- 
nes sobre las consecuencias de la dislocación de comunidades cerradas y el subsecuente desarraigo de sus miembros. En The Suffrage of Elvira, el proceso electoral saca a la superficie la inoperancia de las estructuras coloniales - simples copias de modelos europeos-, así como el encasillamiento artificial de los diferentes grupos étnicos. Las elecciones son inútiles, pues se fundamentan en una ética carente de compromiso ideológico. Lo que predomina es el interés personal y los personajes están dispuestos a sacrificar sus lealtades culturales por una posición de poder. El problema es que su comportamiento y su éxito final se dan dentro de la rigidez de una estructura a la que de un modo u otro traicionan; es decir, no se propone ningún tipo de negociación o compromiso sino que se deja de lado las jerarquías establecidas por los dos grupos raciales (negros y de color) y las tres comunidades religiosas (la cristiana, la hindú y la musulmana).

Tanto The Mystic Masseur como The Suffrage of Elvira tratan acerca del ascenso al poder de personajes esencialmente mediocres pero que son capaces de ajustarse a los vacíos morales causados por el desarraigo cultural. Sin embargo, su caracterización va más allá de la simple descripción de su medianía: la densidad narrativa y la cantidad de alusiones intertextuales los convierten en símbolos de mimetismo poscolonial. La ambiguiedad no puede ser más clara al tratar de describir la profesión de Ganesh en The Mystic Masseur. En su definición de diccionario masseur es simplemente un masajista, pero Naipaul parte de los ecos producidos por dicho término para resaltar los logros de dicho personaje. Más que masajista, es un médico improvisado (¿será el término curandero demasiado despectivo?) cuya reputación se funda en los mil quinientos libros que cubren las paredes de su habitación. Acomplejado en la escuela por su nombre hindú y sus orígenes rurales, se promete hacer de su vida algo trascendental. Y lo logra: además de ser profesor de primaria, su misticismo le gana el respeto de su comunidad, al grado de convertirlo en líder político que con el tiempo obtiene el honor de ser un MBE, Miembro de la Orden del Imperio Británico, otorgado por el rey. Deja de usar turbante, dhoti y koortah, para vestirse elegantemente con trajes europeos, y se mimetiza a tal grado con la cultura dominante que cambia su nombre Pundit Ganesh Ramsumair por el de "G. Ramsay Muir, MBE", después de imitar las actitudes de Gandhi y de iniciar sus discursos con una contundente frase tomada del escritor indio Narayan: "Amigos míos..." (Naipaul 1957). Una vez más, deja los rasgos esenciales de su personalidad y de su identidad india para convertirse en una especie de actor que desempeña los roles necesarios para superar el anonimato. Al igual que los vecinos de la calle Miguel, se construye una imagen pública que termina por eclipsar su verdadero ser. 
Así como Pundit Ganesh se convierte en tema de un calipso, que narra irónicamente sus aventuras y socava así la vacua importancia de sus logros, de igual forma la paródica lucha electoral de The Suffrage of Elvira no es más que una guerra de lemas publicitarios carentes de sustancia, los cuales representan la falta de compromiso real de los candidatos con la sociedad. Este marco externo dificulta la de por sí ambigua lectura de la novela. Obviamente, no es que los personajes tengan una intención maquiavélica por destacar, sino que su situación social y su falta de conciencia histórica y política los llevan a intentar sacar el mayor provecho de las elecciones. El resultado de un enfoque de este tipo es que, de hecho, Naipaul simplifica y menosprecia la historia de Trinidad y del Caribe, de tal modo que, en lugar de explorar con mayor perspicacia las polaridades ideológicas de una sociedad multicultural que ha tenido que luchar contra un pasado de esclavitud y opresión, nos ofrece una sociedad estratificada y limitada por las instituciones europeas que, al ser transplantadas al nuevo mundo, han perdido su función y sus valores. Así, la trama de The Suffrage of Elvira reduce la mayor parte de los acontecimientos a las posturas supersticiosas e ignorantes de los personajes, las cuales llevan a situaciones cómicas, pero a la vez transmite la imposibilidad de cualquier tipo de desarrollo. Una vez más, la aparente comicidad esconde la visión pesimista de Naipaul. Por ejemplo, la descripción del perro abandonado, Tiger, que tiene ataques de hipo y aparece en los mítines, se torna casi una farsa cuando la población le atribuye al animal poderes sobrenaturales. Una vez que el lector comprende la estrategia narrativa de Naipaul, se cuestiona si este tipo de situaciones son verdaderamente humorísticas o si no son más que un mecanismo tendencioso con el que Naipaul manipula el contexto histórico y los movimientos sociales de su país de origen.

En este sentido, la densidad textual que caracteriza toda su obra se convierte en un arma de doble filo pues, en una primera lectura, el lector suele quedarse sólo con la capa más visible de la narración, la trama, y por tanto con una visión distorsionada del texto. En este nivel, las situaciones cómicas y los rasgos humorísticos parecen ser contundentes. Sin embargo, un análisis más minucioso revela una cantidad asombrosa de subtextos que van generando diferentes interpretaciones. Aquí es donde la excepcional maestría de Naipaul se torna incómoda y muchas veces dolorosa, pues la activación interpretativa de cada uno de los subtextos crea nuevos hilos conductores a la vez que libera y transforma sus significados. Cada episodio puede ser leído, entonces, desde una perspectiva diferente, según el subtexto o los subtextos que lo sustenten. La variedad de subtextos es notable, e incluye alusiones y referencias filosóficas, históricas, mi- 
tológicas, literarias, culinarias, cinematográficas, antropológicas, etcétera, que se entrecruzan sin cesar.

La intertextualidad ofrece alternativas narrativas a una visión unilateral (europea) de la historia, pero también obliga al lector a cuestionar cada situación. Por ejemplo: la fotografía enmarcada del encuentro de Mahatma Gandhi con el rey Jorge V en la Conferencia de la Mesa Redonda preside la sala o el estudio de varios de los personajes. Dentro de un contexto histórico general, la fotografía produce ya dos connotaciones que repercuten en la interpretación de la novela: por un lado, Gandhi como la figura central del movimiento independentista de la India en un momento culminante de su proceso de negociación con el gobierno británico; por el otro, el choque de culturas evidente en la vestimenta que usa cada personaje: Gandhi en su atuendo característico y el rey vestido formalmente de frac. Considerando la actitud sonriente de los dos estadistas, uno supone que el motivo de la reunión fue todo un éxito, pero nada está más lejos de la verdad. La Conferencia de la Mesa Redonda consistió en una serie de reuniones convocada por el gobierno británico con el objeto de estudiar la creación de una constitución para la India. Las tres etapas se llevaron a cabo en Londres. La primera se realizó de noviembre de 1930 a enero de 1931, pero no contó con la presencia del Congreso Nacional de la India, el partido de Gandhi, el cual se encontraba en una campaña de desobediencia civil. Gandhi asistió a la segunda, que se efectuó de septiembre a diciembre de 1931 y fue, en realidad, un fracaso, pues no se llegó a ningún acuerdo, entre otras razones porque Gandhi dio un discurso beligerante en el que acusaba a los británicos (y al sistema capitalista que implementaron) de haber roto el equilibrio de las relaciones sociales de su país. La cordialidad expresada en la fotografía es, entonces, sólo una fachada, pero si recordamos que la India finalmente logró su independencia, de alguna manera representa la importancia de las negociaciones políticas que dan voz, después de todo, a las naciones colonizadas.

Este breve resumen histórico nos ayuda a comprender la complejidad de la prosa de Naipaul y la forma en que un recurso metonímico como el de esta fotografía le permite no sólo introducir de forma encubierta sus sagaces juicios morales, sino también incidir en el desarrollo de la acción, al dejar que la fotografía aparezca en momentos estratégicos de la narración. La fotografía (y lo que representa) sirve como contrapunto de las decisiones de los personajes, pero también es el centro de escenas verdaderamente chuscas, como cuando un fruto del árbol del pan de Ramlogan cae con tal fuerza sobre el techo de la casa de Chittaranjan que tira la fotografía y desencadena la furia de este último, quien maldice en hindi y considera el accidente como una verdadera afrenta de su vecino, lo que lo lleva a pensar en vengarse con 
algún tipo de brujería. En el mundo diegético de la novela, Chittaranjan y Ramlogan encarnan a la vieja generación de indios en Trinidad, los que no pueden ni quieren ajustarse a los cambios de la sociedad. En este caso, la fotografía es sólo un pretexto para justificar la reacción del personaje y dejar ver las supersticiones que rigen su vida (Naipaul 1958: 95-96).

A pesar de la insistencia de los críticos en que la comicidad de las primeras obras de Naipaul deja ver un grado de afecto y empatía que el autor ha perdido con el tiempo, creo que cabe reflexionar sobre los recursos empleados para lograr dicha comicidad y sobre el motivo ulterior que la sustenta. En Naipaul, el humorismo es una técnica de distanciamiento que, en última instancia, ofrece una representación muy particular y limitada del contexto histórico, al grado que cabría preguntarse, como lo hace Suman Gupta, si la historia de Trinidad es verdaderamente pertinente para el mundo diegético del autor (Gupta 1999: 12). Dada la importancia que suele atribuírsele al contex to histórico-social en la obra de Naipaul, ésta es una reflexión válida, pero no hace más que generar más dudas en cuanto a la forma de leer a dicho autor. Uno admira su maestría narrativa, pero también cuestiona su visión final y la forma en que llega a ella. Como dijo una vez Derek Walcott, lo que ofende a los caribeños no es tanto el contenido sino el estilo de sus obras (Walcott 1962: 18-19). No es gratuito que Naipaul se haya distanciado cada vez más de su país de origen y que, al obtener el Nobel, lo haya borrado como fuente de creación artística, pues sólo reconoció lo que la India e Inglaterra le habían aportado. Pero Naipaul es, definitivamente, un escritor polémico y enigmático, que pone el dedo en la llaga en lo que se refiere a la situación del mundo poscolonial, a la inoperancia de sus instituciones y al desorden general de sus sociedades. Por eso hay que leerlo.

\section{Bibliografía}

Bhabha, Homi. 1994. The Location of Culture. Londres: Routledge.

Cudjoe, Selwyn R. 1988. V. S. Naipaul. A Materialist Reading. Amherst: The University of Massachusetts Press.

Donnell, Alison y Sarah Lawson Welsh. 1996. The Routledge Reader in Caribbean Literature. Londres: Routledge.

Fanon, Frantz. 1952. Peau Noire, Masques Blancs. París: Editions du Seuil, 1965. 
Gupta, Suma. 1999. V. S. Naipaul. Plymouth: Northcote House/The British Council. (Serie Writers and their Work)

Naipaul, V. S. 1957. The Mystic Masseur. Londres: Picador, 2001. 1958. The Suffrage of Elvira. Londres: Penguin, 1969. 1959. Miguel Street. Londres: Penguin, 1971.

Walcott, Derek. 1962. "History and Picong... in the Middle Passage". Critical Perspectives on Derek Walcott. Ed. de Robert D. Hamner. Boulder/Londres: A Three Continents Book/Lynne Rienner Publishers, 1997. 